\title{
Effects of a Quaternary Lidocaine Derivative, QX-314, on Slow Ventral Root Potentials in Neonatal Rats
}

\author{
Hayakawa $C^{1}$, Inagaki $K^{1}$, Minoura $\mathrm{Y}^{2}$ and \\ Onimaru $\mathrm{H}^{3 *}$ \\ ${ }^{1}$ Department of Orthopedic Surgery, Showa University \\ School of Medicine, Hatanodai, Shinagawa-ku, Tokyo, \\ Japan \\ ${ }^{2}$ Departments of Medicine Division of Cardiology, Showa \\ University School of Medicine, Hatanodai, Shinagawa-ku, \\ Tokyo, Japan \\ ${ }^{3}$ Department of Physiology, Showa University School of \\ Medicine, Hatanodai, Shinagawa-ku, Tokyo, J apan \\ *Correspondling author: Onimaru H, Department \\ of Physiology, Showa University School of Medicine, \\ Hatanodai, Shinagawa-ku, Tokyo, J apan
}

Received: December 08, 2016; Accepted: December 27, 2016; Published: December 29, 2016

\begin{abstract}
The use of QX-314 (a quaternary derivative of lidocaine) in the clinical setting has been proposed to achieve the selective inhibition of nociceptors that express transient receptor potential vanilloid 1 (TRPV1) channels with fewer motor deficits. It has been established that slow ventral root potential induced by ipsilateral dorsal root stimulation in the isolated (typically lumbar) spinal cord of newborn rats reflects the nociceptive response. This in vitro experimental model is useful for assessing the actions of analgesics. However, there is no report regarding the effects of QX-314 and the combined application of capsaicin in the in vitro experimental model. Therefore, we examined the effects of extracellularly applied QX-314 and capsaicin on the spinal reflex response in spinal cord preparations from newborn rats. We found that co-application of QX-314 $(1 \mathrm{mM})$ and capsaicin $(10 \mu \mathrm{M})$ caused significant attenuation of the reflex response that continued after washout. We suggest that QX-314 passed into neurons in the reflex arc through TRPV1 channels activated by capsaicin. Our report further provides the basic neuronal mechanisms to support the clinical use of QX-314 that seems to be potentially expected for analgesic treatment.
\end{abstract}

Keywords: QX-314; Nociceptive response; Newborn rat; in vitro

\section{Abbreviations}

ACSF: Artificial Cerebrospinal Fluid; DRG: Dorsal Root Ganglion; QX-314; Lidocaine N-Ethyl Bromide; TRPV1: Transient Receptor Potential Vanilloid 1

\section{Introduction}

A quaternary derivative of lidocaine, QX-314, is thought to be membrane impermeable due to its positive charge and to produce local anesthetic effects when it is intra cellularly administered to neurons [1,2]. Binshtok et al [3] reported that the extracellular application of QX-314 in neurons of Dorsal Root Ganglion (DRG) could block nociceptors when it was applied together with capsaicin (a transient receptor potential vanilloid 1 [TRPV1] agonist) because QX-314 could permeate through the TRPV1 channels that were opened by capsaicin [4-6]. Thus, the clinical use of QX-314 has been proposed to achieve the selective inhibition of nociceptors that express TRPV1 channels with fewer motor deficits [3]. It has been established that the slow ventral root potential induced by ipsilateral dorsal root stimulation in the isolated (typically lumbar) spinal cord of newborn rats reflects the nociceptive reflex. This in vitro experimental model is useful for assessing the actions of analgesics [7-9]. Dexmedetomidine and morphine inhibited slow ventral root potentials following ipsilateral dorsal root stimulation in newborn rat spinal cord preparation in vitro [10]. We recently reported that lidocaine depressed nociception-related responses at lower concentrations than those that induced respiratory depression [11]. However, there is no report regarding the effects of QX-314 and combined application of capsaicin on nociception-related responses in the above in vitro experimental model. Therefore, we examined the effects of extracellularly applied QX-314 and capsaicin on the spinal reflex response in spinal cord preparations from newborn rats.

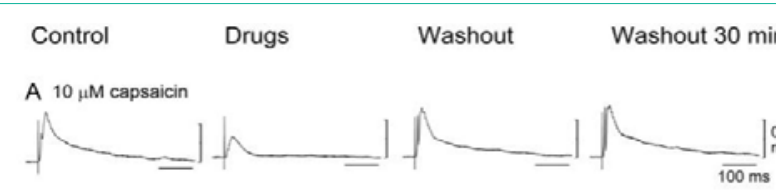

B $1 \mathrm{mM}$ QX-314
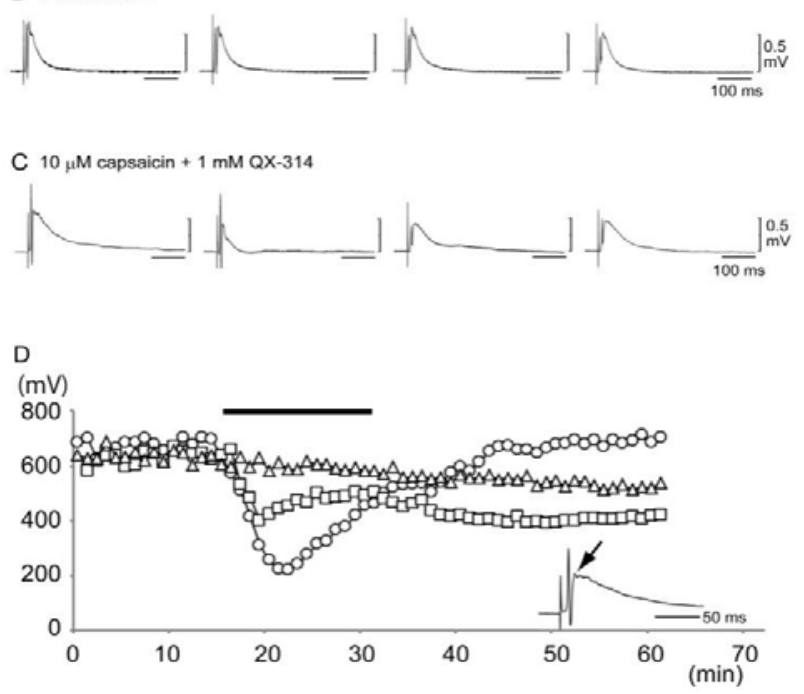

Figure 1: Effects of QX-314 on spinal reflex responses. A, Application of $10 \mu \mathrm{M}$ capsaicin. B, Application of $1 \mathrm{mM} \mathrm{QX}-314$. C, Co-application of $10 \mu \mathrm{M}$ capsaicin and $1 \mathrm{mM}$ QX-314. Control, before drug application; Drug, 4-6 min after drug application; Washout, at $15 \mathrm{~min}$ after drug application; Washout $30 \mathrm{~min}$, after 30min washout of drug. Each recording shows an average from three responses. D, Time course of changes of the amplitude of the slow ventral root potential in the reflex response. Inset, Example of a fast-sweep representation of the reflex response in which the arrow denotes the peak of the slow ventral root potential whose amplitude is plotted.
Austin J Anesthesia and Analgesia - Volume 4 Issue 2 - 2016 ISSN : 2381-893X | www.austinpublishing group.com Onimaru et al. (C) All rights are reserved
Citation: Hayakawa C, Inagaki K, Minoura Y and Onimaru H. Effects of a Quaternary Lidocaine Derivative, QX314, on Slow Ventral Root Potentials in Neonatal Rats. Austin J Anesthesia and Analgesia. 2016; 4(2): 1051 


\section{Materials and Methods}

\section{Preparation and solutions}

The experimental protocols were approved by the Animal Research Committee of Showa University, which operates in accordance with Law No.105 (of the Japanese Government) for the care and use of laboratory animals. Spinal cord preparations were isolated from Wistar rats (postnatal day 0-3) under deep isoflurane anesthesia. The preparations then were cut transversely between the L1 and L5 nerve roots. Preparations were superfused continuously at $2.5-3 \mathrm{ml} / \mathrm{min}$ in a $2 \mathrm{ml}$ chamber with artificial cerebrospinal fluid (ACSF) [12] composed of (in mM) $124 \mathrm{NaCl}, 5.0 \mathrm{KCl}, 1.2 \mathrm{KH}_{2} \mathrm{PO}_{4}, 2.4$ $\mathrm{CaCl}_{2}, 1.3 \mathrm{MgCl}_{2}, 26 \mathrm{NaHCO}_{3}$, and 30 glucose and equilibrated with $95 \% \mathrm{O}_{2}$ and $5 \% \mathrm{CO}_{2}$ at a $\mathrm{pH}$ of 7.4 . The preparations were maintained at a temperature of $25-26^{\circ} \mathrm{C}$. Lidocaine N-Ethyl Bromide (QX-314) was purchased from Sigma-Aldrich (Tokyo, Japan) and was stocked as a $100 \mathrm{mM}$ solution in purified water. Drugs were dissolved with the above-described ACSF and bathapplied.

To evaluate the effects of QX-314 on putative nociceptive responses, the ipsilateral dorsal root of L3 was stimulated using a glass suction electrode, and the induced reflex response was recorded from the $\mathrm{L} 3$ ventral root through a $0.5 \mathrm{~Hz}$ high-pass filter. The dorsal root was stimulated every 60 s with a $5-20 \mathrm{~V}, 200 \mu$ s square pulse. We measured the peak amplitude of the slow ventral root potentials $[10,13]$. The preparations were superfused with ACSF for at least 1530 min until the spinal reflex response became stable. Then, capsaicin and/or QX-314 were bath applied for $15 \mathrm{~min}$ and washed out.

\section{Data analysis}

All data analyses were performed using the Lab Chart 7 Pro software program (AD Instruments, Castle Hill, Australia). The data are presented as the mean and standard deviation for all preparations. The significance of the values was analyzed by one-way ANOVA followed by a Tukey-Kramer multiple comparisons test (Graph Pad In Stat; Graph Pad Software Inc., La Jolla, CA, USA) at a confidence level of $\mathrm{P}<0.05$.

\section{Results and Discussion}

Figurel shows typical examples of the time course of changes in reflex responses after the application of $10 \mu \mathrm{M}$ capsaicin, $1 \mathrm{mM}$ QX-314 or $10 \mu \mathrm{M}$ capsaicin plus $1 \mathrm{mM}$ QX-314. Sole application of capsaicin induced a transient decrease of the reflex response followed by recovery even during capsaicin treatment (Figure 1A, open circles in D). Sole application of QX-314 tended to result in a slow and slight (but not significant) decrease of the reflex response (Figure 1B, open triangles). Co-application of capsaicin and QX314 induced a rapid decrease of the reflex response without recovery (Figure 1C, open squares in D). The group data are summarized in Figure 2. Although a tendency for the reflex response to decrease was observed with the co-application of capsaicin and QX-314 (10 or 100 $\mu \mathrm{M})$, a significant change was confirmed only in the case of $1 \mathrm{mM}$ QX-314 (Figure 1 and Figure 2, Figure 2C). Previous studies have reported that extracellularly applied QX-314 passes into cells through capsaicin-activated TRPV1 channels [3-6]. Our present results were consistent with these previous observations. We have suggested that TRPV1 channels are expressed in cells of the spinal cord [14]. It was thought that QX-314 passed into neurons in the reflex arc through

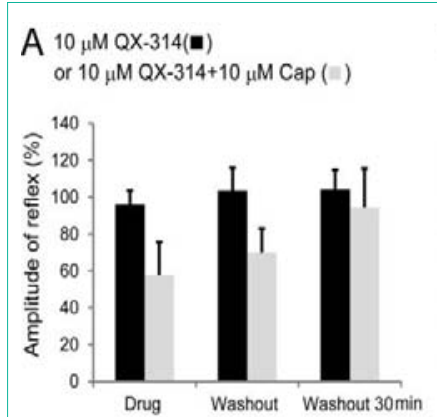

B $100 \mu \mathrm{MQX}-314(\mathbf{m})$

or $100 \mu \mathrm{M}$ QX-314+10 $\mu \mathrm{M}$ Cap ( )

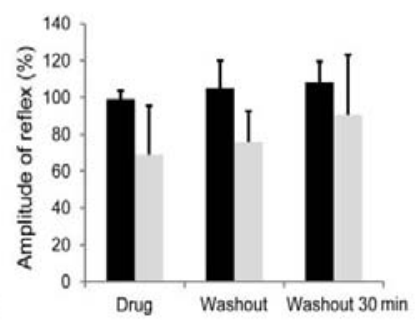

C $1 \mathrm{mM} \mathrm{QX-314( \boldsymbol {a } )}$

or $1 \mathrm{mM}$ QX-314+10 $\mu \mathrm{M}$ Cap ( $)$

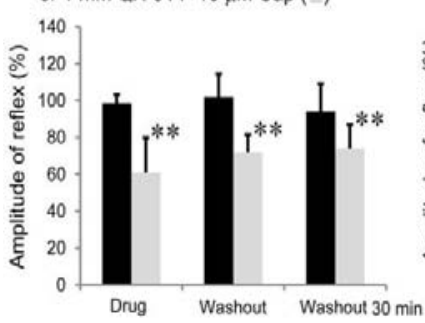

$\mathrm{D} 10 \mu \mathrm{M}$ Cap (घ)

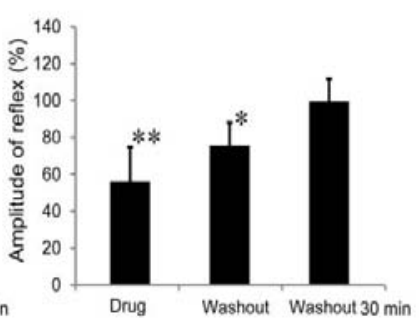

Figure 2: Summary of the effects of $Q X-314$ on amplitude of the reflex response. Black bars in A-C, sole application of $Q X-314$. Gray bars in A-C, combined application of QX-314 and capsaicin. A, 10 $\mu \mathrm{M}$ QX-314 $(n=6)$ or

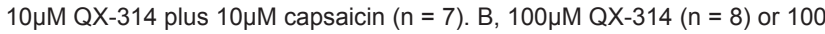
$\mu \mathrm{M} Q X-314$ plus $10 \mu \mathrm{M}$ capsaicin $(n=5)$. C, $1 \mathrm{mM} Q X-314(n=8)$ or $1 \mathrm{mM} Q X-$ 314 plus $10 \mu \mathrm{M}$ capsaicin $(n=14)$. D, $10 \mu \mathrm{M}$ capsaicin $(n=9)$. ${ }^{\star} P<0.05,{ }^{\star *} P<0.01$, in comparison to the control values.

TRPV1 channels activated by capsaicin. Rivera-Acevedo et al [15] reported that QX-314 exerts biphasic effects on the TRPV1 channels, inhibiting the capsaicin-evoked TRPV1 current sat lower (micro molar) concentrations and activating TRPV1channels at higher (millimolar) concentrations. In the experiments on DRG neurons by Binshtok et al [3], 5mM QX-314 was used. Although DRG neurons were not included in the reflex arc of our experiments, our results indicated that $1 \mathrm{mM}$ QX-314 was necessary to induce significant effects.

Several reports have shown that the sole application of extracellular QX-314 could affect the action potentials $[2,16]$ and that it produced long-lasting local anesthesia with a slow onset in animal models in vivo [17]. We previously reported that the extracellular application of QX-314 induced inhibitory effects on respiratory activity in the brainstem-spinal cord preparation isolated from newborn rats, and the combined application of capsaicin (10 or $100 \mu \mathrm{M})$ with QX-314 $(100 \mu \mathrm{M})$ showed no additional effect [18]. Because depressive effects of neuronal activity in the central nervous system could be induced by micro molar concentrations of QX-314 $[18,19]$, such side effects should be considered for the use of QX-314 in clinical cases. Moreover, co-application of capsaicin with QX-314 is not practical in clinical use. Thus, to achieve the selective inhibition of nociceptors that express TRPV1 channels with fewer motor deficits [3], co-application of QX-314 and lidocaine (or bupivacaine) instead of capsaicin has been suggested to be clinically more useful $[3,20]$.

\section{Conclusion}

Our report further provides the basic neuronal mechanisms 
to support the clinical use of QX-314 that seems to be potentially expected for analgesic treatment, although consideration of the side effects would be necessary.

\section{Acknowledgements}

This work was supported by Grants-in-Aid for Scientific Research (KAKENHI: 25430012).

\section{References}

1. Narahashi T, Frazier DT, Moore JW. Comparison of tertiary and quaternary amine local anesthetics in their ability to depress membrane ionic conductances. J Neurobiol. 1972; 3: 267-276.

2. Strichartz GR. The inhibition of sodium currents in myelinated nerve by quaternary derivatives of lidocaine. J Gen Physiol. 1973; 62: 37-57.

3. Binshtok AM, Bean BP, Woolf CJ. Inhibition of nociceptors by TRPV1 mediated entry of impermeant sodium channel blockers. Nature. 2007; 4 607-610.

4. Ries CR, Pillai R, Chung CC, Wang JT, et al. QX-314 produces long-lasting local anesthesia modulated by transient receptor potential vanilloid receptors in mice. Anesthesiology. 2009; 1: 122-126

5. Gerner P, Binshtok AM, Wang CF, Hevelone ND, Bean BP, Woolf CJ, et al. Capsaicin combined with local anesthetics preferentially prolongs sensory/ nociceptive block in rat sciatic nerve. Anesthesiology. 2008; 5: 872-878.

6. Puopolo M, Binshtok AM, Yao GL, Oh SB, Woolf CJ, Bean BP. Permeation and block of TRPV1 channels by the cationic lidocaine derivative QX-314. J Neurophysiol. 2013; 7: 1704-1712.

7. Otsuka M, Konishi S. Electrophysiology of mammalian spinal cord in vitro. Nature. 1974; 252: 733-734.

8. Kendig JJ, Savola MK, Woodley SJ, Maze M. Alpha 2-adrenoceptors inhibit a nociceptive response in neonatal rat spinal cord. Eur J Pharmacol. 1991; 2: $293-300$.

9. Faber ES, Chambers JP, Evans RH. Depression of NMDA receptor-mediated synaptic transmission by four alpha2 adrenoceptor agonists on the in vitro rat spinal cord preparation. Br J Pharmacol. 1998; 3: 507-512.
10. Otsuguro K, Yasutake S, Ohta T, Ito S. Effects of opioid receptor and alpha2adrenoceptor agonists on slow ventral root potentials and on capsaicin and formalin tests in neonatal rats. Brain Res Dev Brain Res. 2005; 158: 50-58.

11. Shakuo T, Lin ST, Onimaru H. The effects of lidocaine on central respiratory neuron activity and nociceptive-related responses in the brainstem-spinal cord preparation of the newborn rat. Anesth Analg.2016; 5; 1586-1593.

12. Suzue T. Respiratory rhythm generation in the in vitro brain stem-spinal cord preparation of the neonatal rat. J Physiol. 1984; 354: 173-183.

13. Tsuzawa K, Minoura Y, Takeda S, Inagaki K, Onimaru H. Effects of a2adorenoceptor agonist dexmedetomidine on respiratory rhythm generation of newborn rats. Neurosci Lett. 2015; 597: 117-120.

14. Tani M, Kotani S, Hayakawa C, Lin ST, Irie S, Ikeda K, et al. Effects of a TRPV1 agonist capsaicin on respiratory rhythm generation in brainstemspinal cord preparation from newborn rats. Pflugers Arch. 2016; in press

15. Rivera-Acevedo RE, Pless SA, Ahern CA, Schwarz SK. The quaternary lidocaine derivative, QX-314, exerts biphasic effects on transient receptor potential vanilloid subtype 1 channels in vitro. Anesthesiology. 2011; 6: 14251434.

16. Omana-Zapata I, Khabbaz MA, Hunter JC, Bley KR. QX-314 inhibits ectopic nerve activity associated with neuropathic pain. Brain Res. 1997; 2: 228-237.

17. Lim TK, Macleod BA, Ries CR, Schwarz SK. The quaternary lidocaine derivative, QX-314, produces long-lasting local anesthesia in animal models in vivo. Anesthesiology. 2007; 2: 305-311.

18. Takahashi K, Hayakawa C, Onimaru H. Effects of a quaternary lidocaine derivative, QX-314, on the respiratory activity in brainstem-spinal cord preparation from newborn rats. Neurosci Lett. 2016; 619: 121-125.

19. Cheung HM, Lee SM, MacLeod BA, Ries CR, Schwarz SK. A comparison of the systemic toxicity of lidocaine versus its quaternary derivative QX-314 in mice. Can J Anaesth. 2011; 5: 443-450.

20. Brenneis C, Kistner K, Puopolo M, Jo S, Roberson D, Sisignano M, et al. Bupivacaine-induced cellular entry of QX-314 and its contribution to differential nerve block. Br J Pharmacol. 2014; 2: 438-451.
Austin J Anesthesia and Analgesia - Volume 4 Issue 2 - 2016 ISSN : 2381-893X | www.austinpublishing group.com Onimaru et al. (C) All rights are reserved
Citation: Hayakawa C, Inagaki K, Minoura Y and Onimaru H. Effects of a Quaternary Lidocaine Derivative, QX314, on Slow Ventral Root Potentials in Neonatal Rats. Austin J Anesthesia and Analgesia. 2016; 4(2): 1051 